\title{
Who Told You That? Uncovering the Source of Believed Cues to Deception
}

\author{
Carolyn M. Hurley ${ }^{1}$, Darrin J. Griffin² \& Michael A. Stefanone ${ }^{2}$ \\ ${ }^{1}$ Undergraduate Degree Programs in Singapore, University at Buffalo, Singapore \\ ${ }^{2}$ Department of Communication, University at Buffalo, Buffalo, New York, USA \\ Correspondence: Carolyn Hurley, University at Buffalo, Undergraduate Degree Programs in Singapore, 461 \\ Clementi Rd, USA. Tel: 1-65-6248-9152. E-mail: churley5@buffalo.edu
}

Received: December 11, $2013 \quad$ Accepted: December 27, $2013 \quad$ Online Published: January 23, 2014

doi:10.5539/ijps.v6n1p19

URL: http://dx.doi.org/10.5539/ijps.v6n1p19

\begin{abstract}
Many beliefs about deceptive communication - like liars avoid eye contact - are popular but inaccurate. To better understand the transmission of both accurate and false cues to deception, we examined the perceived source of deception beliefs. Two exploratory studies revealed six categories of belief sources such as observed behavior, mass media, and social networks, derived from 19 categories of deception beliefs. Reported beliefs loaded onto three primary factors suggesting a simpler schema for detecting deception. Both studies revealed that most people recalled learning about cues to deception from observing others' behavior, however, inaccurate beliefs were more likely to be perpetuated by credible sources.
\end{abstract}

Keywords: deception, beliefs, eye contact, source, schema

\section{Transmitting Believed Cues to Deception}

\subsection{Understanding the Problem}

Across cultures most people believe that liars "avoid eye contact" and "appear nervous" (Global Deception Research Team [GDRT], 2006) even though there is no scientific evidence supporting these beliefs. Relying on inaccurate beliefs may lead to poor deception detection ability in interpersonal relationships, by juries, business persons and security professionals (Bond \& DePaulo, 2006). While there is global agreement on believed cues to deception, research has yet to examine why these beliefs exist or are perpetuated despite their inaccuracy. The first step in the process is to identify the source of beliefs to understand who is disseminating such inaccurate information.

Source credibility could be one factor facilitating the diffusion of inaccurate beliefs. Individuals may not question credible sources like authority figures, more experienced coworkers, or published research. For example, police officers learn inaccurate beliefs through their formal training, which may damage their deception detection ability (Kassin \& Fong, 1999). American children are told by their parents to "look them in the eye" while telling the truth (Einav \& Hood, 2008), shaping inaccurate beliefs about lying behavior from a young age. Information about deception is also broadcasted in the popular media (e.g., Lie to Me) and portrayals often leave consumers believing erroneous cues.

The two studies presented herein provide the first systematic investigation into the source of deception beliefs. The first study uses latent content analysis to examine open-ended responses regarding beliefs about deceptive behavior and identifies categories for both beliefs and the origins of those beliefs. The second study examines the reliability, utility and inter-correlations of these categories. First we present a discussion of the available research on the origins of deception beliefs, which supports these two studies.

\subsection{Differences in Believed and Actual Cues to Deception}

Believed cues to deception are the verbal and nonverbal behaviors people stereotypically associate with lying (Feeley \& Young, 2000). The impacts of deception beliefs are relevant as we all make daily judgments as to whether our friends, coworkers, or acquaintances are telling the truth. Many beliefs about deception reflect the stereotypical view that a liar is nervous, fidgety, and ashamed; although these beliefs are inaccurate (Reinhard, Scharmach, \& Müller, 2013) they may be used as a guide to make judgments. 
There is considerable debate regarding the relationships between behavioral cues and deception, given that cues seem to vary as a product of the type of lie, experimental design, and relationship between liar and target (Sporer $\&$ Schwandt, 2007). Although no specific behavior is a direct product of deception, researchers generally agree that certain behaviors associated with increased cognition, emotional arousal, and story preparation manifest more often in deceptive as compared to truthful communication. Meta-analyses reveal that liars generally provide less detailed, less plausible and often shorter stories, are less involved and immediate, show greater uncertainty, and are more nervous than truth tellers (DePaulo et al., 2003; Sporer \& Schwandt, 2006). However, these "indicators" of deception are context dependent and vary greatly based on variables like the liar's motivation, the spontaneity of the event, and even the study's experimental design (DePaulo et al., 2003; Sporer \& Schwandt, 2006, 2007).

Beliefs about deception are more consistent across contexts and communicators with global beliefs emerging such as that all liars avoid eye contact (e.g., GDRT, 2006). While this cue is not an actual sign of deception (DePaulo et al., 2003; Sporer \& Schwandt, 2007), it is a behavior frequently controlled by deceivers because many people believe eye contact is a sign of deception. Thus, they exploit this behavioral norm to appear truthful (McCarthy \& Lee, 2009). Deception belief studies have found a preponderance of inaccurate beliefs (see DePaulo et al., 2003; Sporer \& Schwandt, 2006, 2007), such as the perception that hand, arm, and leg movements, self-manipulators, shrugs, and postural shifts all increased during deception (e.g., Akehurst, Kohnken, Vrij, \& Bull, 1996; GDRT, 2006; Gordon, Baxter, Rozelle, \& Druckman, 1987; Vrij \& Semin, 1996).

Kinesic cues including postural shifts, facial movements, and fidgeting, are also popularly reported deception beliefs. However, the research is mixed regarding their actual relationship to deception (for an overview, see DePaulo et al., 2003). These cues may be predictive of actual deception in high-stakes situations (e.g., ten Brinke \& Porter, 2012), however the relationship is more complex than spotting a smile or shaking leg resulting in misunderstanding on the part of the observer. For example, some scholars argue that liars may reveal facial cues in high-pressure situations (e.g., Frank \& Ekman, 1997), but these expressions are difficult to identify in real time (Ekman \& Friesen, 1969, 1974). So while correctly identified subtle facial expressions may lead a target to detect a lie (Warren, Schertler, \& Bull, 2009), the average observer may misapply this relationship by thinking that certain facial expressions always give liars away (Strömwall, Granhag, \& Hartwig, 2004).

Body language is often used as an all-encompassing term for kinesic movements, which may mask its relationship to deception given the wide range of behaviors in this category with varying ties to cognition, emotion, and attempted control. While hand, foot, and leg movements often decrease with deception, general head movements are not predictive of veracity (Sporer \& Schwandt, 2007). Nervousness is another indicator that is frequently reported and has some relationship to deception (DePaulo et al., 2003); however, this cue does not hold a consistent definition (e.g., measured as speech rate, DePaulo, Rosenthal, Rosenkrantz, \& Green, 1982; and fidgeting, Mann, Vrij, \& Bull, 2004) generating some doubt regarding its utility as a deception detection cue.

According to the deception literature, beliefs with the strongest scientific support are related to story construction (e.g., plausibility and consistency; DePaulo et al., 2003) and mental effort (e.g., speech errors and pauses; Walczyk, Roper, Seeman, \& Humphrey, 2003). Overall, individuals who are able to attend to and utilize a combination of verbal and nonverbal indicators (Ekman \& O'Sullivan, 1991) that are empirically supported and not based on deception "stereotypes" (Reinhard et al., 2013) tend to be the most accurate at detecting deception. Lakhani and Taylor (2003) suggest that deception detection schemata likely develop from memories of such events, but scholars have not yet tested the notion that these psychological impressions are based on a combination of channels, cues, and experiences.

\subsection{Understanding the Origins of Deception Beliefs}

Several studies have examined deception beliefs across cultures and contexts, finding global agreement in beliefs such as eye contact (GDRT, 2006). Other studies examining diverse groups of participants including students and adults, law enforcement officers, teachers, and managers have also found relatively few differences between groups (see Granhag, Andersson, Strömwall, \& Hartwig, 2004). Generally, differences exist in the intensity of a cue belief (e.g., small or large changes with deception), but not in the direction of the belief (e.g., Colwell, Miller, Miller, \& Lyons, 2006; Hart, Hudson, Fillmore, \& Griffith, 2006; Strömwall et al., 2004; Vrij, Akehurst, \& Knight, 2006).

This broad level of agreement suggests beliefs may originate from macro-level sources including popular media or societal norms, rather than more individualized or personal experiences. In fact, the moral teaching of what is right and wrong may provide a stereotype of what a liar is; specifically someone, "stricken with shame, wracked by the threat of exposure, liars leak signs of their inner torment. They fidget, avoid eye contact, and can scarcely 
bring themselves to speak" (Bond \& DePaulo, 2006, p. 216). Across cultures people are taught that lying is an immoral act - rather than an everyday occurrence - which may lead to stereotypical views of deceptive behavior (see also Vrij, 2008). A similar hypothesis put forth by GDRT (2006) suggests that individual perceptions may represent social norms passed from one generation to the next; however this proposition has not been systematically evaluated. The existence of sources that promote stereotypical views of deception (see Kassin \& Fong, 1999) provides further explanation for why the average person is a poor lie detector - he is focusing on cues that do not characterize all types of lies, or cues that are simply inaccurate. Lie detectors may be looking for nervous, avoidant, emotional individuals who have committed grave sins, not the potentially calmer, normal individual like themselves who are comfortable with lying, lie often, and for un-selfish and face-saving reasons (DePaulo \& Kashy, 1998).

A few notable works have proposed possible origins for practitioner beliefs about deceptive behavior which may also inform our study of origins. Potential sources include police training manuals, more experienced officers, a high rate of deception encounters, creation of explanations for ambiguous events, and confirmation bias (Strömwall et al., 2004; Vrij, 2008). These sources perpetuate the same inaccurate stereotypical assumptions of liars being nervous, defensive, and experiencing guilt, and in daily life most individuals only look to confirm these beliefs in their interactions (Strömwall et al., 2004). These proposed origins may generalize beyond practitioners; there is an increased access to literature about deception - as well as documentaries, criminal proceedings, etc. - on the Internet. Additionally, personal relationships can be a regular source for information about deception beliefs.

The extant literature provides interesting propositions regarding the source of believed cues to deception. More systematically identifying these sources is an important step toward understanding their dissemination. While it may not be possible to pinpoint the exact moment a deception belief is transmitted, identifying the perceived source of one's beliefs is a crucial step in the exploration of the origins of cue beliefs. Thus, we propose the following research question:

$R Q 1$ : What are the perceived origins of deception beliefs?

Individuals are more likely to trust messages from credible sources; therefore the answer to this question may reside in sender and source credibility characteristics. Following this notion we propose an additional question:

$R Q 2$ : Do accurate and inaccurate deception beliefs derive from different sources?

This is a difficult question to answer given that individuals may not be able to recall these formative experiences with absolute precision. Nisbett and Wilson (1977) argued that we tend to report more than we know when responding to survey items. This is one type of response bias researchers must contend with when designing survey measures (Krosnick, 1999). However, since the current research is interested in perceptions and it is impossible to observe participants during the formation of those perceptions, the only option is to rely on recall data. While individuals may not be able to perfectly recall the source of deception beliefs, this is less important when questioning the perceived source of a belief. If individuals believe they learned about avoiding eye contact from a credible source, they may be more likely to use this knowledge when both engaging in and detecting deception.

\subsection{Organizing Beliefs about Deception}

One purpose of gathering source data is to increase our understanding of the deception judgment process. As we examined beliefs about deception, we noted that previous studies grouped beliefs into broader categories based on channel of behavior - such as verbal or nonverbal (Ekman \& O'Sullivan, 1991), or verbal, visual, or paralinguistic (Anderson, DePaulo, Ansfield, Tickle, \& Green, 1999) - to understand if belief in certain channels of cues affected deception detection accuracy. These studies did not agree on which channel of beliefs (e.g., a combination of verbal and nonverbal, Ekman \& O'Sullivan, 1991; or paralinguistic only, Anderson et al., 1999) was more helpful in detecting deception. This leads to questions regarding the underlying organization and use of deception beliefs by observers.

Zuckerman, DePaulo, and Rosenthal (1981) suggest that behavioral cues to deception exist because lying stimulates more arousal, activates emotions, is more cognitively complex, and results in more behavioral control than truth telling. While many studies examine specific cues to deception (e.g., eye contact, plausibility, etc.), the majority of these cues are connected to at least one of the four rationales provided by Zuckerman and colleagues. It is possible that individuals rely on these broader ideas about deceptive behaviors, as opposed to looking for specific cues among a wide array of possibilities. Use of broader impressions, also suggested by Strömwall and 
colleagues (2004), would reveal simpler processes for evaluating truthfulness than indicated by current models of deception detection that suggest we chose from a list of options.

Practically, forming general impressions of a sender's behavior may provide more parsimonious approaches to evaluating deception. While extant research suggests a complex taxonomy of deception-related behavior, it remains unclear whether they are the guiding framework for judging deception. Following this notion we propose the following research question:

$R Q 3$ : Is there an underlying factor structure for beliefs about deception?

\subsection{Methodological Considerations}

Our knowledge of deception beliefs comes from capturing participants' perceptions via survey measures, associating deception judgments to target behaviors, or asking participants to describe their judgment process. While our knowledge is enhanced by these studies, each of these paradigms presents methodological limitations (e.g., limit or artificially guide participant response) that may hinder our understanding of deception beliefs and their origins. Given the wide array of cues that liars may show (DePaulo et al., 2003), our study builds on the work of GDRT (2006), which attempted to overcome these limitations by collecting open-ended responses about deception beliefs which were coded into 103 categories - a significantly longer list than is presented in any other published research. GDRT's second study (2006) confirmed the top 10 beliefs, although the less frequently reported cues (comprising 44\% of responses) were largely ignored. Given the exploratory nature of our study, we adopted a similar approach to gather a full range of data on beliefs about deception and their perceived origins.

While extant research has provided interesting ideas regarding sources of perceived cues to deception, validation of these propositions is required. Identifying the perceived sources of beliefs aids our understanding on why inaccurate beliefs about deception persist. Thus we designed two studies to empirically examine the origins of believed cues to deception. Our methods were constructed to overcome limitations of previous work and to initiate research directed towards identifying the sources of deception beliefs.

\section{Study 1}

\subsection{Method}

\subsubsection{Participants and Procedure}

One hundred sixty one students (55.9\% female) from the University at Buffalo anonymously completed questionnaires addressing beliefs about lying and truth telling. The majority of participants were Caucasian $(70.8 \%)$ and on average $19.8(S D=4.80)$ years old. The institutional review board approved all procedures.

\subsubsection{Measures}

The questionnaire captured basic demographic information, followed by questions regarding participants' beliefs about deceptive behavior. The first open-ended question asked, In general, what evidence or clues do you use when deciding if another person is lying? Ample space was provided to record as many beliefs as could be generated by each participant. Next, participants identified the most important clue, the source of the belief, and the age they learned the clue. Participants were asked to be as detailed as possible.

\subsubsection{Response Coding}

A category scheme was developed for the open-ended questions based solely on participants' responses. The first author and an additional coder utilized latent content analysis and constant comparative techniques (Glaser \& Strauss, 1967; Strauss \& Corbin, 1990) to independently review all of the surveys and develop categories for each set of responses. This form of content analysis is used in exploratory research in which coding categories are derived directly from the raw data by constantly comparing the responses from all participants. The categories were collapsed until all of the resulting categories and definitions were mutually exclusive. This process was completed for the deception belief and reported origin responses. A miscellaneous category was included to capture responses that did not correspond to the devised categories.

Next, manifest content analysis was used to code for the presence or absence of each deception belief or origin category in the response data. Independent coders examined all of the raw data, compared each item to the category codes and assigned a category to each data point in this step of the analysis. Each code was used a maximum of one time for each participant's response. For example, if a participant responded that she believed that "sweating, rapid eye movements, increased respiration, and avoidance of eye contact" were cues to deception, then just the category codes eye contact and physiological cues would be recorded, even though the participant mentioned two aspects of eye behavior and two physiology cues. Through an iterative coding process, 
the coders achieved acceptable levels of reliability; Cohen's (1960) Kappa met or exceeded 0.70 for 18 of the 20 categories. Every instance of disagreement was resolved through discussion, resulting in $100 \%$ agreement.

Table 1. Definitions and study 1 reliability of deception beliefs and origins categories

\begin{tabular}{|c|c|c|c|}
\hline Category Name & Definition & $\begin{array}{l}\% \text { of Sample } \\
\text { Mentioning }\end{array}$ & $\begin{array}{c}\text { Initial } \\
\text { Reliability }\end{array}$ \\
\hline \multicolumn{4}{|l|}{ Beliefs } \\
\hline 1- Eye Contact & $\begin{array}{l}\text { Target is looking around, not making direct eye contact, or } \\
\text { his/her eyes are wandering or shifting. }\end{array}$ & $72.0 \%$ & 0.960 \\
\hline 2- Fidgeting & $\begin{array}{l}\text { Target is fidgeting, twitching, or showing manipulators such } \\
\text { as wringing/rubbing of hands or body. }\end{array}$ & $27.3 \%$ & 0.912 \\
\hline 3- Speech Errors & $\begin{array}{l}\text { Speech involves stuttering, repetition, misuse of words, or } \\
\text { mumbling. }\end{array}$ & $24.8 \%$ & 0.947 \\
\hline 4- Facial Expression & Target's facial expressions give him/her away. & $23.6 \%$ & 0.907 \\
\hline 5- Nervousness & Target increases in signs of anxiety or unease. & $21.1 \%$ & 0.882 \\
\hline 6- Pitch \& Intonation & $\begin{array}{l}\text { Speech involves change in vocal pitch, vocal tone, or } \\
\text { intonation. }\end{array}$ & $19.9 \%$ & 0.905 \\
\hline 7- Body Language & $\begin{array}{l}\text { Any mention of body language or movement that does not } \\
\text { involve the face or fidgeting (unspecified). }\end{array}$ & $18.6 \%$ & 0.897 \\
\hline 8- Contradictions & Target changes his/her story. & $15.5 \%$ & 0.908 \\
\hline 9- Physiological Cues & $\begin{array}{l}\text { Changes in target's internal body behavior in which external } \\
\text { cues are present: such as increased respiration and } \\
\text { perspiration, change in face color, or increased heart rate. }\end{array}$ & $13.7 \%$ & 0.958 \\
\hline 10- Plausibility & $\begin{array}{l}\text { Any questions of the sincerity of the target's story, or } \\
\text { likelihood that the story could happen. }\end{array}$ & $11.8 \%$ & 0.815 \\
\hline 11- Hesitations & $\begin{array}{l}\text { Target shows long pauses while answering or thinking of } \\
\text { response. }\end{array}$ & $11.2 \%$ & 0.880 \\
\hline 12- Behavior Change & $\begin{array}{l}\text { Observer notes changes in target's baseline (normal) } \\
\text { behavior, often based on previous experience with target } \\
\text { (providing him/her with additional information about target's } \\
\text { normal behavior). }\end{array}$ & $11.2 \%$ & 0.737 \\
\hline 13- Attitude & $\begin{array}{l}\text { Target changes in approach to the conversation, including } \\
\text { changes in manner, stance, posture, or target displays } \\
\text { attitudes such as defensiveness, overconfidence or sarcasm. }\end{array}$ & $9.3 \%$ & 0.822 \\
\hline 14- Avoidance & $\begin{array}{l}\text { Target physically or vocally distances him/herself from } \\
\text { observer, by moving away from observer, or providing } \\
\text { vague or indirect responses. }\end{array}$ & $8.7 \%$ & 0.576 \\
\hline $\begin{array}{l}\text { 15- Inappropriate } \\
\text { Positive Affect }\end{array}$ & Target increasingly laughs or smiles during the interaction. & $8.1 \%$ & 0.923 \\
\hline 16- Speech Rate & Target's rate of speech changes. & $6.8 \%$ & 0.944 \\
\hline 17- Uncertainty & $\begin{array}{l}\text { Target shows doubt or lacks confidence when responding } \\
\text { (either in voice, words, or body language). }\end{array}$ & $6.2 \%$ & 0.899 \\
\hline 18- Elevated Affect & $\begin{array}{l}\text { Target displays change in mood or emotional state (such as } \\
\text { increased anger response). }\end{array}$ & $4.3 \%$ & 0.919 \\
\hline 19- Emotionless & $\begin{array}{l}\text { Target remains stoic, showing no change in facial movement } \\
\text { or demeanor. }\end{array}$ & $1.9 \%$ & 0.795 \\
\hline 20- Miscellaneous & $\begin{array}{l}\text { Partial or whole response cannot be classified in any other } \\
\text { category. }\end{array}$ & $41.0 \%$ & 0.612 \\
\hline
\end{tabular}




\section{Origins}

1- Observed Behavior

2- Mass Media

3- Social Networks

4- Personal Behavior

5- A Priori

6- Academia

7- Miscellaneous
Subject has learned from personal experience with others lying, or has witnessed or observed these behaviors from watching others.

Subject has learned about these behaviors from mass media outlets such as television, news reports, the Internet, or topical books (not scientific publications).

Subject heard about this belief from family, friends or close contacts.

Subject reports exhibiting these behaviors when he/she lies.

Subject has "always known" or known from a young age that these behaviors are indicators of deception, or believes it is widely known or instinctual that these behaviors are indicators (common sense).

Subject has learned behaviors from the publication of scientific research, presentations at conferences or in courses, through formal schooling or informal learning.

Subject does not provide valid respond, or response cannot be classified according to previous categories.
$52.2 \%$

$18.6 \%$

0.969

$16.8 \%$

0.898

$13.0 \%$

0.945

$7.5 \%$

0.868

$5.6 \%$

0.867

$9.9 \%$

The twenty categories of deception cue beliefs and seven categories of origins that emerged from the coding process are displayed in Table 1.

\subsection{Results}

On average each participant described 3.6 different beliefs $(S D=1.3)$, resulting in a total of 575 deception belief responses. Most participants (72\%) mentioned eye contact as a cue to deception, followed by fidgeting, speech errors, facial expression, and nervousness (more than $20 \%$ of the sample). Eye contact was reported as the most frequently used belief by half of the sample (50.3\%), with the remainder of participants distributed among 17 other categories (physiological cues and speech rate were not mentioned). Only facial expression and contradictions were mentioned by more than $5 \%$ of the sample.

Seventy-eight percent of participants reported only one origin, with a total of 200 statements on origins elicited. The most frequently reported origin was observed behavior, with $52 \%$ of the sample mentioning they learned beliefs from interacting with deceptive others. The mass media, social networks, and personal behavior were mentioned with similar frequency (see Table 1). Additional categories such as a priori (common sense) and academia also emerged, however these sources were identified less frequently.

Table 2. Reported origins of the most frequently used deception beliefs in study 1

\begin{tabular}{lcccccccc}
\hline & & \multicolumn{6}{c}{ Proportion of Sample Reporting Each Origin } \\
\cline { 3 - 8 } Belief Category & Sample & $\begin{array}{c}\text { Observed } \\
\text { Behavior }\end{array}$ & $\begin{array}{c}\text { Mass } \\
\text { Media }\end{array}$ & $\begin{array}{c}\text { Social } \\
\text { Networks }\end{array}$ & $\begin{array}{c}\text { Personal } \\
\text { Behavior }\end{array}$ & A Priori & Academia & Misc. \\
\hline Eye Contact & $50.30 \%$ & $57 \%$ & $25 \%$ & $21 \%$ & $10 \%$ & $6 \%$ & $9 \%$ & $7 \%$ \\
Facial & & & & & & & & \\
Expression & $6.80 \%$ & $55 \%$ & $9 \%$ & $18 \%$ & $9 \%$ & $9 \%$ & - & $18 \%$ \\
Contradictions & $5.60 \%$ & $33 \%$ & - & $22 \%$ & $22 \%$ & $11 \%$ & - & $22 \%$ \\
Body Language & $4.30 \%$ & $29 \%$ & $14 \%$ & $14 \%$ & $14 \%$ & $14 \%$ & $14 \%$ & - \\
\hline
\end{tabular}

The origins of the most frequently reported beliefs and associated origins are presented in Table 2 . 


\subsection{Discussion}

This data confirmed several of the sources proposed by Strömwall and colleagues (2004), such as a transmission from academic sources (similar to training manuals), social networks, and personal beliefs [RQ1]. Regardless of belief most participants reported learning about behavioral cues to deception from watching others, revealing few source differences based on accuracy of belief [RQ2]. Given the number of hypothetical "others" present in our interactions, these data suggests that a myriad of sources encourage inaccurate beliefs about deception.

Some participants mentioned multiple origins for specific deception beliefs, therefore creating an unforeseen issue interpreting the data. The majority of participants reported learning about deceptive cues during adolescence $(M=11.6$ years, $S D=3.7)$, casting doubt on the credibility of their memory processes. However, some participants provided detailed descriptions of origins such as "Mike Caro's Book of Poker Tells", suggesting they remembered the details of belief acquisition with some confidence.

While most responses validated perceptions found in previous research a handful of novel categories, such as avoidance, behavior change, attitude, and elevated affect, emerged. Similar themes have only been mentioned on a few occasions, using different operationalizations (Mann et al., 2004; Masip, Garrido, Herrero, Antón, \& Alonso, 2006). Additionally, several participants mentioned cues that were not easily classified in any defined category, suggesting that there may be idiosyncratic beliefs not easily categorized or that are suppressed when using lists provided by researchers.

\section{Study 2}

The first study explored college students' thoughts about deceptive behavior by allowing them to discuss their perceptions in their own words. We designed Study 2 to replicate and extend the findings in Study 1 by examining the relationship among the categories of beliefs and sources while utilizing a quantitative method with a new sample of participants.

\subsection{Method}

\subsubsection{Participants and Procedure}

An additional two hundred five students (49.3\% female) were recruited from the same university as Study 1 to participate in research regarding beliefs about truth and lies. The majority of the students were Caucasian $(75.1 \%)$ and on average $20.8(S D=1.70)$ years old. All participants anonymously completed the questionnaire in class.

\subsubsection{Measures}

The questionnaire consisted of three sections prompting forced-choice responses. After collecting basic demographic data, the survey presented the nineteen deception beliefs and definitions that emerged in Study 1 (less the miscellaneous category) and asked participants to rate how often they used each clue $(1=$ Never, $5=$ All the time $)$ and how helpful they found each clue $(1=$ Not helpful at all, $5=$ Extremely helpful $)$. The final section presented the six origins with their definitions and asked participants to choose one of the listed origins (or select I don't remember or none of the above) for each of their top three most utilized clues. Participants were also asked to list the age when they first learned about their top three clues.

\subsection{Results}

Table 3. Descriptives and origins of the most frequently used deception beliefs in study 2

\begin{tabular}{|c|c|c|c|c|c|c|c|c|c|}
\hline \multirow[b]{2}{*}{$\begin{array}{l}\text { Category } \\
\text { Name }\end{array}$} & \multirow[b]{2}{*}{ Freq. } & \multirow{2}{*}{$\begin{array}{l}\text { Avg. } \\
\text { Use } \\
\text { M } \\
\text { (SD) }\end{array}$} & \multicolumn{7}{|c|}{ Proportion of Sample Reporting Each Origin } \\
\hline & & & $\begin{array}{l}\text { Observed } \\
\text { Behavior }\end{array}$ & $\begin{array}{l}\text { Mass } \\
\text { Media }\end{array}$ & $\begin{array}{c}\text { Social } \\
\text { Networks }\end{array}$ & $\begin{array}{l}\text { Personal } \\
\text { Behavior }\end{array}$ & $\begin{array}{c}\text { A } \\
\text { Priori }\end{array}$ & Academia & $\begin{array}{c}\text { Don't } \\
\text { Remember } \\
\text { or None }\end{array}$ \\
\hline Eye Contact & 100 & $\begin{array}{c}3.72 \\
(0.95)\end{array}$ & $46.9 \%$ & $12.2 \%$ & $6.1 \%$ & $10.2 \%$ & $11.2 \%$ & $9.2 \%$ & $4.1 \%$ \\
\hline Fidgeting & 29 & $\begin{array}{c}3.23 \\
(1.11)\end{array}$ & $42.9 \%$ & $17.9 \%$ & $7.1 \%$ & $7.1 \%$ & $10.7 \%$ & $10.7 \%$ & $3.6 \%$ \\
\hline Speech Errors & 23 & $\begin{array}{c}3.50 \\
(1.14)\end{array}$ & $39.1 \%$ & $13.0 \%$ & - & $34.8 \%$ & - & $13.0 \%$ & - \\
\hline
\end{tabular}




\begin{tabular}{|c|c|c|c|c|c|c|c|c|c|}
\hline $\begin{array}{l}\text { Facial } \\
\text { Expression }\end{array}$ & 33 & $\begin{array}{c}3.77 \\
(1.07)\end{array}$ & $53.1 \%$ & $9.4 \%$ & $3.1 \%$ & $9.4 \%$ & $9.4 \%$ & $15.6 \%$ & - \\
\hline Nervousness & 41 & $\begin{array}{c}3.78 \\
(0.99)\end{array}$ & $40.0 \%$ & $12.5 \%$ & $5.0 \%$ & $27.5 \%$ & $5.0 \%$ & - & $10.0 \%$ \\
\hline $\begin{array}{l}\text { Pitch \& } \\
\text { Intonation }\end{array}$ & 7 & $\begin{array}{c}2.87 \\
(1.13)\end{array}$ & $28.6 \%$ & $14.3 \%$ & $14.3 \%$ & $42.9 \%$ & - & - & - \\
\hline $\begin{array}{l}\text { Body } \\
\text { Language }\end{array}$ & 46 & $\begin{array}{r}3.04 \\
(1.21)\end{array}$ & $40.9 \%$ & $11.4 \%$ & $6.8 \%$ & $4.5 \%$ & $9.1 \%$ & $13.6 \%$ & $13.7 \%$ \\
\hline Contradictions & 108 & $\begin{array}{c}4.52 \\
(0.78)\end{array}$ & $53.8 \%$ & $11.5 \%$ & $1.0 \%$ & $12.5 \%$ & $14.4 \%$ & $5.8 \%$ & $1.0 \%$ \\
\hline $\begin{array}{l}\text { Physiological } \\
\text { Clues }\end{array}$ & 14 & $\begin{array}{c}3.28 \\
(1.26)\end{array}$ & $53.8 \%$ & $7.7 \%$ & - & $15.4 \%$ & $15.4 \%$ & $7.7 \%$ & - \\
\hline Plausibility & 36 & $\begin{array}{c}3.74 \\
(1.12)\end{array}$ & $37.1 \%$ & $5.7 \%$ & $2.9 \%$ & $17.1 \%$ & $25.7 \%$ & $8.6 \%$ & $2.9 \%$ \\
\hline Hesitations & 30 & $\begin{array}{c}3.52 \\
(1.14)\end{array}$ & $60.0 \%$ & $4.0 \%$ & - & $32.0 \%$ & $4.0 \%$ & - & - \\
\hline $\begin{array}{l}\text { Behavior } \\
\text { Change }\end{array}$ & 25 & $\begin{array}{c}3.66 \\
(1.03)\end{array}$ & $48.0 \%$ & $8.0 \%$ & - & $24.0 \%$ & $4.0 \%$ & $8.0 \%$ & $8.0 \%$ \\
\hline Attitude & 28 & $\begin{array}{c}3.76 \\
(1.10)\end{array}$ & $55.6 \%$ & - & $3.7 \%$ & $25.9 \%$ & $7.4 \%$ & - & $7.4 \%$ \\
\hline Avoidance & 37 & $\begin{array}{c}3.50 \\
(1.12)\end{array}$ & $54.1 \%$ & $2.7 \%$ & $10.8 \%$ & $18.9 \%$ & $2.7 \%$ & - & $10.8 \%$ \\
\hline $\begin{array}{l}\text { Inappropriate } \\
\text { Pos. Affect }\end{array}$ & 5 & $\begin{array}{r}3.00 \\
(1.15)\end{array}$ & $50.0 \%$ & - & - & $25 \%$ & - & $25 \%$ & - \\
\hline Speech Rate & 5 & $\begin{array}{c}2.64 \\
(1.13)\end{array}$ & $60.0 \%$ & - & - & $20.0 \%$ & - & $20.0 \%$ & - \\
\hline Uncertainty & 19 & $\begin{array}{r}3.39 \\
(1.06)\end{array}$ & $63.2 \%$ & $5.3 \%$ & - & $15.8 \%$ & $15.8 \%$ & - & - \\
\hline $\begin{array}{l}\text { Elevated } \\
\text { Affect }\end{array}$ & 9 & $\begin{array}{r}3.47 \\
(1.04)\end{array}$ & $77.8 \%$ & - & - & $11.1 \%$ & - & $11.1 \%$ & - \\
\hline Emotionless & 9 & $\begin{array}{c}2.42 \\
(1.21)\end{array}$ & $22.2 \%$ & $11.1 \%$ & - & $33.3 \%$ & $11.1 \%$ & $22.2 \%$ & - \\
\hline
\end{tabular}

Table 3 presents the reported origins associated with participants' strongest beliefs. The variables frequency of use and helpfulness were strongly positively related (all $r$ 's $>.633, p<.001$ ), hence only the former variable is reported (Table 3). Participants most frequently reported looking for contradictions when judging veracity. Eye contact was rated significantly lower than contradictions in terms of frequency of use ratings $(t(204)=11.042, p$ $<.001$ ), although it was the second most frequently reported belief when participants chose their "top" three cues to deception. All categories were chosen at least once as one of the three most important cues used to determine a person's honesty.

An exploratory factor analysis examined the relationships among the 19 cues. The Kaiser-Meyer-Olkin measure (.87) of sampling adequacy was used to determine factorability and was above the recommended value of .6 . Bartlett's test of sphericity was also significant $\left(\chi^{2}(171)=1009.05, p<.01\right)$. The communalities were all well above .3 further indicating shared variance among the 19 variables. Principal component analysis was used with a varimax rotation method to explore the underlying factor structure among the items. 
Table 4. Exploratory factor analysis loadings for beliefs from study 2

\begin{tabular}{lccc}
\hline & \multicolumn{3}{c}{ Factor Loading } \\
\cline { 2 - 4 } Belief Category & $\mathbf{0 . 6 8 2}$ & 0.088 & 0.284 \\
Elevated Affect & $\mathbf{0 . 6 3 7}$ & 0.074 & 0.254 \\
Uncertainty & $\mathbf{0 . 6 1 3}$ & 0.451 & -0.196 \\
Speech Rate & $\mathbf{0 . 5 8 6}$ & 0.168 & 0.023 \\
Pitch \& Intonation & $\mathbf{0 . 5 5 2}$ & 0.040 & 0.416 \\
Attitude & $\mathbf{0 . 5 3 4}$ & 0.368 & 0.027 \\
Inappropriate Positive Affect & $\mathbf{0 . 4 3 3}$ & 0.203 & 0.185 \\
Physiological Cues & & & \\
& 0.225 & $\mathbf{0 . 7 2 4}$ & 0.137 \\
Fidgeting & -0.030 & $\mathbf{0 . 6 8 6}$ & 0.266 \\
Eye Contact & 0.251 & $\mathbf{0 . 6 0 4}$ & 0.089 \\
Body Language & 0.161 & $\mathbf{0 . 4 8 4}$ & 0.412 \\
Facial Expression & 0.251 & $\mathbf{0 . 4 5 1}$ & 0.381 \\
Behavior Change & & & \\
Contradictions & -0.034 & 0.128 & $\mathbf{0 . 7 8 9}$ \\
Plausibility & 0.168 & 0.069 & $\mathbf{0 . 6 6 3}$ \\
Hesitations & 0.162 & 0.215 & $\mathbf{0 . 5 3 6}$ \\
Avoidance & 0.353 & 0.257 & $\mathbf{0 . 4 8 4}$ \\
\hline Note. Exal & & & \\
\end{tabular}

Note. Extraction Method: Principal Component Analysis; Rotation Method: Varimax with Kaiser Normalization

The three factor model that emerged is presented in Table 4. Speech errors, nervousness, and emotionless loaded on an unused fourth factor. The fourth factor was abandoned because the three cues were thematically ambiguous and appeared to lack a theoretical basis for grouping. Thus, a more theoretical three factor model was adopted. The three factor solution was confirmed upon examination of the scree plot and explained $44 \%$ of the total variance. The first factor, labeled Emotion \& Arousal, explained $31 \%$ of the variance when examining initial eigenvalues while the second resulting factor, Nonverbal Behavior, explained $7 \%$ of the variance. The third factor, Verbal Content, explained an additional $6 \%$ of the variance in the model. The overall correlations of the three families (Emotion \& Arousal, Nonverbal Behavior, and Verbal Content) of deception beliefs were $.76, .72$, and .63 respectively.

Participants chose a single origin response for each of their three "top cues". Observed behavior was the most frequently reported source for every deception cue with the exception of pitch \& intonation, which was listed as the most important by only seven participants. Three of these seven participants cited personal behavior as the belief origin for this cue. Overall, the next most frequent origin for all beliefs was personal behavior followed by the mass media and social networks.

The mean age participants reported first learning about these cues fell into middle to late adolescence. Speech rate was the only cue deviating from this age group $(M=13.50$ years old). Although participants could easily select that they did not remember where they learned about a cue or their source was not listed on the form (i.e., none of the above), only a small portion of the sample chose these options.

Chi squares were conducted to examine whether the reported origins differed within each of the families of cues. Tests for Emotion \& Arousal and Nonverbal Behavior were not significant, however, a Chi square for Verbal Content revealed a significant difference in the patterns of the origins, $\chi^{2}(21)=44.341, p=.002$. Residuals revealed that more participants "just knew" (a priori) about plausibility than expected, and more participants learned about avoidance from social networks or didn't remember the origin, than expected. 
We also examined origins by general cue family. A Chi square revealed a significant difference in the pattern of sources among the three families, $\chi^{2}(14)=24.219, p=.043$. While the general pattern emphasizing observed behavior held consistent, these analyses revealed that more people learned about Nonverbal Behavior cues from academia than expected.

\subsection{Discussion}

Study 2 utilized the findings of the open-ended responses from Study 1 to further explore deception beliefs and their origins. Although eye contact was still among the most highly rated cues, it was reportedly used less than contradictions (and four other beliefs) when participants rated the beliefs on a 1 to 5 point scale (Table 3). However when participants were asked to list their "top" beliefs, eye contact was again at the top of the ranking. It is possible that participants' beliefs are not concrete, given the variability in responses within the same survey instrument.

This study also examined the grouping of deception beliefs. The results suggest that deception beliefs may be organized into smaller groups with strong relationships within them. The first factor, Emotion \& Arousal, suggests that a person might look for global changes in a communicator's feelings to make judgments about his honesty. A deviation from the norm - such as inappropriate positive affect - might signal to an observer that something is out of the ordinary. Beliefs organized into the Nonverbal Behavior family appear to utilize socially constructed norms to identify potential deceptive behavior. It is common to believe that liars have shifty eyes, or leak their true emotions through facial expression or in their body language. This set of cues is not linked to actual cues to deception (e.g., DePaulo et al., 2003). The third factor that emerged from the analysis, Verbal Content, is an interesting family of cues because it appears to focus more on the message itself rather than on the communicator's behavior. The story is scrutinized because it is implausible, inconsistent, or completely avoids an important area of interest. The cues in this family have received support in the literature as strong correlates of deception.

For the most part, reported sources did not differ based on belief or belief family, although some small differences occurred. More people than expected reported learning about Nonverbal Behavior cues from academia, which is interesting given the inconclusive findings in this area. Given the complexity and inconsistencies within the deception research, it is possible that individuals misinterpret what they hear about deceptive behavior or that they over generalize the findings.

\section{General Discussion}

The present study provides descriptive analyses of college students' beliefs regarding deceptive behavior and the origins of these beliefs. Regardless of belief, most participants reported learning about deception from watching others [RQ1]. While specific sources such as topical books, websites, or television shows were mentioned, it appears that most people use knowledge gleaned from interpersonal experiences to guide their judgments.

Results suggest weak links between believed and actual cues to deception, and we propose a few explanations for this finding. First, we know that average people are unreliable lie detectors (Bond \& DePaulo, 2006). Observers seem to use a combination of accurate and inaccurate cues to deception, and are not provided with constructive feedback in their judgment processes, further perpetuating inaccurate stereotypes of deception (McKimmie, Masser, \& Bongiorno, 2013). Second, this finding could suggest that a "chicken and egg" scenario is at play. If we think a person is lying, we may also think we observed suspicious or stereotypical behavior (Levine, Asada, \& Park, 2006). A recent meta-analysis revealed that some strongly held beliefs about deception (e.g., gaze aversion) were unrelated to actual deception judgment, supporting this notion (Hartwig \& Bond, 2011). Third, individuals may even be creating these beliefs - either on the spot or during the deception encounter - to rationalize others' behavior. As individuals try to make sense of their world, they often create explanations for occurrences that are ambiguous or that they do not understand (Strömwall et al., 2004). This same process could apply to survey responses about the origins of deception beliefs - participants reported that they must have learned about these behaviors from watching others because they lacked alternative explanations. Finally, individuals may not be able to accurately recall the cues that give a person away, or where they learned such cues (Nisbett \& Wilson, 1977). Their survey responses may reflect mental biases towards a priori causal theories.

Taken together, this suggests that participants may not have actually seen the cues they reported learning from "observation". It is difficult to determine whether individuals are actually observing cues in their interactions with others, or if people think they see specific behaviors in deceptive others. To better understand the judgment process, future research would benefit by employing specific judgment tasks in which the cues exhibited by 
deceivers are carefully analyzed and linked to reported strategies and beliefs. This is a difficult task given both the number of deceptive behaviors and the variability in types of lie scenarios an observer could encounter.

Given the majority of participants reported learning all beliefs from observed behavior, it was difficult to identify whether accurate and inaccurate beliefs derived from different sources [RQ2]. However, our examination of the underlying factor structure of the beliefs revealed both relationships among the beliefs (labeled here as "families"), as well as small differences in the reported origins of each belief family.

Our analyses revealed three "families" of beliefs we labeled as Emotion \& Arousal, Nonverbal Behavior, and Verbal Content [RQ3]. The most "accurate" beliefs fell into the category of Verbal Content, whereas the other two belief families revealed mixed scientific support. Emotion \& Arousal cues such as pupil dilation (physiological cues), increased pitch, and verbal uncertainty, are scientifically supported, whereas speech rate and increased smiling (inappropriate positive affect) are not supported across meta-analyses (DePaulo et al., 2003; Sporer \& Schwandt, 2007). Examining Nonverbal Behavior beliefs is more difficult, as researchers may not agree on how to define and code these broader categories. When "facial expression" refers to smiling, there is generally no relation to deception (Sporer \& Schwandt, 2007). However, when the experimental design involves emotional lies, differentiating facial expressions occur significantly more in deception (e.g., Ekman \& Friesen, 1974; Frank \& Ekman, 1997). While avoiding eye contact is generally not related to deception (DePaulo et al., 2003), it also becomes a better predictor when the lie involves feelings (Sporer \& Schwandt, 2007). Body language can include foot and leg movements, which generally decrease during deception, or posture shifts, which have no consistent relation to deception (Sporer \& Schwandt, 2007). This suggests that the accuracy of Nonverbal Behavior beliefs are dependent on definition, measurement, and experimental design, and these cues are considered more controversial in the literature.

When examining the origins of these belief families, we found some differences in reported source of Nonverbal Behavior beliefs as compared to the other two families [RQ2]. More individuals reported learning about Nonverbal Behavior cues from academia than expected, which was surprising given that the Nonverbal Behavior family could be considered the least supported set of beliefs in the literature. These cues are also more complex (e.g., detecting micro expressions) than other deception beliefs (e.g., hesitations and pitch). While some individuals may believe they learned about these cues from academic sources such as class lectures or research, it is possible that they misunderstood the source or misinterpreted due to limited exposure or understanding.

The relationships among beliefs may suggest that only a few beliefs drive participants' judgments when engaging in deception detection. This seems logical as many judgment processes are not consciously controlled (Greenwald \& Krieger, 2006) and our judgments are frequently limited by available cues (Brunswik, 1952; Funder, 1999). While researchers traditionally have measured belief in deception cues as individual-level phenomena, this might not represent the most parsimonious explanation for how individuals judge others. While most beliefs seem to "fit" within three families (e.g., hesitations, contradictions, and plausibility clearly relate to the verbal message or structure); theory does not perfectly explain the association of some beliefs (e.g., avoidance could be seen as a physical behavior in addition to verbal behavior). These family names should be seen as provisional and these categories should be investigated further in future research.

Our first study collected descriptive responses rather than quantitative data to explore beliefs about deception and their associated origins. Our qualitative approach identified some novel categories of beliefs including elevated affect, avoidance, and behavior change that were used albeit less frequently. Participants in prior research may have suppressed recollections of behavior they believed betrayed a liar when required to choose from a list of possible responses. While previous studies have gathered considerable data on believed cues to deception, this work suggests the potential for further exploration. The reported use of more popular beliefs such as eye contact and contradictions also appeared to be dependent on data collection method. When participants provided open-ended responses, $50.3 \%$ of the group listed eye contact and $5.6 \%$ of the group listed contradictions as the most important cue. When provided a structured list, participants ranked these cues as equally important. The variation in the results between the two studies suggests that response format can affect both the reported ranking and usefulness of deception beliefs.

Several limitations exist within these studies. We must consider the imperfections of human memory. It is unlikely that all individuals can accurately recall the moment they learned about specific deception cues. Beliefs may also form over a number of years, experiences, and sources given that some participants listed more than one source in their response. The responses collected in this study may best be considered estimates regarding both the age and the source of beliefs about deceptive behavior. While we were primarily concerned with 
individuals' perceptions regardless of accuracy, future research could include judgment tasks to better understand the actual decision-making processes and belief selection when evaluating truthfulness.

Future research regarding deception beliefs and origins should examine generalizability to a variety of contexts, communicators, and types of lies. In this study we asked participants to list cues they used to determine a person's veracity, but were not specific about the context or type of lie. It is possible that this generated a global list of deception cues that are not relevant in every interaction. This may have also limited our ability to see variations across sources; as we could imagine personal experience with a target may lead judgment in an interpersonal context, whereas training and observation direct judgment in professional settings. The coding process employed in Study 1 was different than in previous studies, and a large number of responses were not easily categorized and therefore grouped into a miscellaneous category. Attempts were made to further categorize the miscellaneous data, but no more than three participants shared similar responses. The high frequency with which participants mentioned miscellaneous cues $(11.5 \%$ of all cues) advocates for further investigation of belief source. The categories devised in this study represent broad ideas, and can likely be further defined and analyzed in terms of credibility.

Our findings suggest a simpler schema for how individuals detect deception, which is based largely on information individuals have learned from their experience interacting with others. This provides insight into how beliefs about deception are perpetuated, which can be utilized when teaching others about cues to deception. However, additional research is required to conclusively demonstrate whether these belief schemata and sources persist across the wide variety of deception situations we encounter in our lives.

\section{References}

Akehurst, L., Kohnken, G., Vrij, A., \& Bull, R. (1996). Lay persons' and police officers' beliefs regarding deceptive behaviour. Applied Cognitive Psychology, 10, 461-471. http://dx.doi.org/10.1002/(SICI)1099-0720(199612)10:6<461::AID-ACP413>3.0.CO;2-2

Anderson, D. E., DePaulo, B. M., Ansfield, M. E., Tickle, J. J., \& Green, E. (1999). Beliefs about cues to deception: Mindless stereotypes or untapped wisdom? Journal of Nonverbal Behavior, 23, 67-89. http://dx.doi.org/10.1023/A:1021387326192

Bond, C. F., Jr., \& DePaulo, B. M. (2006). Accuracy of deception judgments. Personality and Social Psychology, 10, 214-234. http://dx.doi.org/10.1207/s15327957pspr1003_2

Brunswik, E. (1952). The conceptual framework of psychology. Chicago, IL: University of Chicago Press.

Cohen, J. (1960). A coefficient of agreement for nominal scales. Educational and Psychological Measurement, 20, 37-47. http://dx.doi.org/10.1177/001316446002000104

Colwell, L. H., Miller, H. A., Miller, R. S., \& Lyons, P. M., Jr. (2006). US police officers' knowledge regarding behaviors indicative of deception: Implications for eradicating erroneous beliefs through training. Psychology, Crime, \& Law, 12, 489-503. http://dx.doi.org/10.1080/10683160500254839

DePaulo, B. M., \& Kashy, D. A. (1998). Everyday lies in close and casual relationships. Journal of Personality and Social Psychology, 74, 63-79. http://dx.doi.org/10.1037/0022-3514.74.1.63

DePaulo, B. M., Lindsay, J. J., Malone, B. E., Muhlenbruck, L., Charlton, K., \& Cooper, H. (2003). Cues to deception. Psychological Bulletin, 129, 74-112. http://dx.doi.org/10.1037/0033-2909.129.1.74

DePaulo, B. M., Rosenthal, R., Rosenkrantz, J., \& Green, C. R. (1982). Actual and perceived cues to deception: A closer look at speech. Basic and Applied Social Psychology, 3, 291-312. http://dx.doi.org/10.1207/s15324834basp0304_6

Einav, S., \& Hood, B. M. (2008). Tell-tale eyes: Children's attribution of gaze aversion as a lying cue. Developmental Psychology, 44, 1655-1667. http://dx.doi.org/10.1037/a0013299

Ekman, P., \& Friesen, W. V. (1969). Nonverbal leakage and cues to deception. Psychiatry, 32, 88-106.

Ekman, P., \& Friesen, W. V. (1974). Detecting deception from the body or the face. Journal of Personality and Social Psychology, 29, 124-129. http://dx.doi.org/10.1037/h0036006

Ekman, P., \& O'Sullivan, M. (1991). Who can catch a liar? American Psychologist, 46, 189-204. http://dx.doi.org/10.1037/0003-066X.46.9.913

Feeley, T. H., \& Young, M. J. (2000). Self-reported cues about deceptive and truthful communication: The effects of cognitive capacity and communicator veracity. Communication Quarterly, 48, 101-119. http://dx.doi.org/10.1080/01463370009385585 
Frank, M. G., \& Ekman, P. (1997). The ability to detect deceit generalizes across different types of high-stake

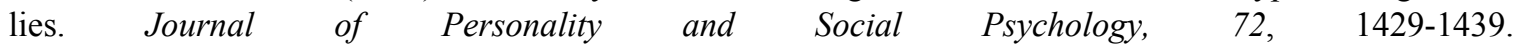
http://dx.doi.org/10.1037/0022-3514.72.6.1429

Funder, D. (1999). Personality judgment: A realistic approach to person perception. San Diego: Academic Press.

Glaser, B. G., \& Strauss, A. L. (1967). The discovery of grounded theory: Strategies for qualitative research. Chicago: Aldine.

The Global Deception Research Team. (2006). A world of lies. Journal of Cross-Cultural Psychology, 37, 60-74. http://dx.doi.org/10.1177/0022022105282295

Gordon, R. A., Baxter, J. C., Rozelle, R. M., \& Druckman, D. (1987). Expectations of honest, evasive, and deceptive nonverbal behavior. Journal of Social Psychology, 127, 231-233. http://dx.doi.org/10.1080/00224545.1987.9713687

Granhag, P. A., Andersson, L. O., Strömwall, L. A., \& Hartwig, M. (2004). Imprisoned knowledge: Criminals beliefs about deception. Legal and Criminological Psychology, 9, 103-119. http://dx.doi.org/10.1348/135532504322776889

Greenwald, A. G., \& Krieger, L. H. (2006). Implicit bias: Scientific foundations. California Law Review, 94, 945-967. http://dx.doi.org/10.2307/20439056

Hart, C. L., Hudson, L. P., Fillmore, D. G., \& Griffith, J. D. (2006). Managerial beliefs about the behavioral cues to deception. Individual Differences Research, 4, 176-184.

Hartwig, M., \& Bond, C. F., Jr., (2011). Why do lie catchers fail? A lens model meta-analysis of human lie judgments. Psychological Bulletin, 137, 643-659. http://dx.doi.org/10.1037/a0023589

Kassin, S. M., \& Fong, C. T. (1999). "I'm innocent!”: Effects of training on judgments of truth and deception in the interrogation room. Law and Human Behavior, 23, 499-516. http://dx.doi.org/10.1023/A:1022330011811

Krosnick, J. A. (1999). Survey research. Annual Review of Psychology, 50, 537-567. http://dx.doi.org/10.1146/annurev.psych.50.1.537

Lakhani, M., \& Taylor, R. (2003). Beliefs about the cues to deception in high- and low-stakes situations. Psychology, Crime \& Law, 9, 357-368. http://dx.doi.org/10.1080/1068316031000093441

Levine, T. R., Asada, K. J. K., \& Park, H. S. (2006). The lying chicken and the gaze avoidant egg: Eye contact, deception, and causal order. Southern Communication Journal, 71, 401-411. http://dx.doi.org/10.1080/10417940601000576

Mann, S., Vrij, A., \& Bull, R. (2004). Detecting true lies: Police officers' ability to detect suspects' lies. Journal of Applied Psychology, 89, 137-149. http://dx.doi.org/10.1037/0021-9010.89.1.137

Masip, J., Garrido, E., Herrero, C., Antón, C., \& Alonso, H. (2006). Officers as lie detectors: Guilty before charged. In D. Chadee, \& J. Young (Eds.), Current themes in social psychology (pp. 187-205). Mona, Jamaica: The University of the West Indies Press.

McCarthy, A., \& Lee, K. (2009). Children's knowledge of deceptive gaze cues and its relation to their actual lying behavior. Journal of Experimental Child Psychology, 103, 117-134. http://dx.doi.org/10.1016/j.jecp.2008.06.005

McKimmie, B. M., Masser, B. M., \& Bongiorno, R. (2013). Looking shifty but telling the truth: The effect of witness demeanor on mock jurors' perceptions. Psychiatry, Psychology, and Law (Advanced online publication). http://dx.doi.org/10.1080/13218719.2013.815600

Nisbett, R. E., \& Wilson, T. D. (1977). Telling more than we know: Verbal reports on mental processes. Psychological Review, 84, 231-259. http://dx.doi.org/10.1037/0033-295X.84.3.231

Porter, S., \& ten Brinke, L. (2008). Reading between the lies: Identifying concealed and falsified emotions in $\begin{array}{llll}\text { universal facial expressions. Psychological } & \text { Science, } & 19, & \text { 508-514. }\end{array}$ http://dx.doi.org/10.1111/j.1467-9280.2008.02116.x

Reinhard, M. A., Scharmach, M., \& Müller, P. (2013). It's not what you are, it's what you know: Experience, beliefs, and the detection of deception in employment interviews. Journal of Applied Social Psychology, 43, 467-479. http://dx.doi.org/10.1111/j.1559-1816.2013.01011.x 
Sporer, S. L., \& Schwandt, B. (2006). Paraverbal indicators of deception: A meta-analytic synthesis. Applied Cognitive Psychology, 20, 421-446. http://dx.doi.org/10.1002/acp.1190

Sporer, S. L., \& Schwandt, B. (2007). Moderators of nonverbal indicators of deception: A meta-analytic synthesis. Psychology, Public Policy, and Law, 13, 1-34. http://dx.doi.org/10.1037/1076-8971.13.1.1

Strauss, A. L., \& Corbin, J. (1990). Basics of qualitative research: Grounded theory procedures and techniques. Newbury Park, C.A.: Sage.

Strömwall, L. A., Granhag, P. A., \& Hartwig, M. (2004). Practitioners' beliefs about deception. In P. A. Granhag, \& L. Strömwall (Eds.), The detection of deception in forensic contexts (pp. 229-250). New York: Cambridge University Press. http://dx.doi.org/10.1017/CBO9780511490071.010

ten Brinke, L., \& Porter, S. (2012). Cry me a river: Identifying the behavioral consequences of extremely high-stakes interpersonal deception. Law and Human Behavior, 36, 469-477. http://dx.doi.org/10.1037/h0093929

Vrij, A. (2008). Detecting lies and deceit: Pitfalls and opportunities (2nd ed.). Chichester: Wiley.

Vrij, A., Akehurst, L., \& Knight, S. (2006). Police officers', social workers', teachers', and the general public's beliefs about deception in children, adolescents and adults. Legal and Criminological Psychology, 11, 297-312. http://dx.doi.org/10.1348/135532505X60816

Vrij, A., \& Semin, G. R. (1996). Lie experts' beliefs about nonverbal indicators of deception. Journal of Nonverbal Behavior, 20, 65-80. http://dx.doi.org/10.1007/BF02248715

Walczyk, J. J., Roper, K. S., Seemann, E., \& Humphrey, A. M. (2003). Cognitive mechanisms underlying lying to questions: Response time as a cue to deception. Applied Cognitive Psychology, 17, 744-755. http://dx.doi.org/10.1002/acp.914

Warren, G., Schertler, E., \& Bull, P. (2009). Detecting deception from emotional and unemotional cues. Journal of Nonverbal Behavior, 33, 59-69. http://dx.doi.org/10.1007/s10919-008-0057-7

Zuckerman, M., DePaulo, B. M., \& Rosenthal, R. (1981). Verbal and nonverbal communication of deception. In L. Berkowitz (Ed.), Advances in experimental social psychology (Vol. 14, pp. 1-59). New York: Academic Press.

\section{Copyrights}

Copyright for this article is retained by the author(s), with first publication rights granted to the journal.

This is an open-access article distributed under the terms and conditions of the Creative Commons Attribution license (http://creativecommons.org/licenses/by/3.0/). 